\title{
The true meaning of the law of five elements (organs' reciprocal dependences and their practical use)
}

\begin{abstract}
Why there is a need to refresh the memory of the acupuncturists about the law of five elements in the ancient Chinese acupuncture? Because up to this moment nobody cared to explain why the organs are related to elements, such as earth, water, fire, metal and wood. And since nobody understands this, the acupuncturists consider it nonsense. This article explains that the ancient law of five elements is very important because it reveals the internal functional dependences of the organs and needs to be taken into consideration at each acupuncture treatment. The article explains for the first time that if elements (earth, water, fire, metal, and wood) were ascribed to each organ, it was done to help the acupuncturists memorize the proportional and reciprocal dependencies among the organs and be able to use them in their acupuncture practice. (This article accentuates on the reciprocal dependences). By knowing the relationship among these elements from everyday life (water extinguishes fire, metal cuts wood, etc.), the acupuncturist was helped to remember the internal functional dependencies of the organs. The article also accentuate on the importance of the ancient knowledge about the relation of the organs to: different parts of the body, different tastes (sweet, sour, bitter, etc.), and different senses (of eyes, nose, ears, mouth). It also accentuates the organs' functional dependence on emotions.
\end{abstract}

Keywords: acupuncture, ancient law of five elements, reciprocal dependencies among organs, organs and body parts, organs and taste, organs and senses, organs and emotion
Volume I2 Issue 3 - 2019

Maria Kuman

Holistic Research Institute, USA

Correspondence: Maria Kuman, Holistic Research Institute, 1414 Barcelona Dr., Knoxville, TN 37923, USA, Email holisticarel@gmail.com

Received: May 03, 2018| Published: June 06, 2019

\section{Introduction}

The ancients believed that energy Chi circulates and activates the organs in a specific order reflected in the "law of five elements" (see the author's book Maria Kuman, Modern Aspects of Ancient Acupuncture). ${ }^{1}$ Y Manaka, et al. ${ }^{2}$ in their book Chasing the Dragon's Tail $^{2}$ explained that the law means that at different times of the day or night the organs are in different phases of their cycles of activity and they consider the "Law of Five Elements" as a "Law of Five Phases". The ancient book ${ }^{3}$ offers the following information for the cycles of organs' activity, which is systematized in the table below.

The table below gives the organs in the order they become active. In a previous article, we discussed the mother-son law, which reflects the strong dependences between the organs. They are also called proportional dependencies and reflect the order in which the organs become active (see the periphery of the pentagram on Figure 1) ${ }^{4}$ Here it is how it applies to acupuncture practice

a. Stimulate with needles the Liver meridian to bring (maximal) energy to the Spleen.

b. Stimulate with needles the Spleen meridian to bring (maximal) energy to the Heart.

c. Stimulate with needles the Heart meridian to bring (maximal) energy to the Lungs.

d. Stimulate with needles the Lung meridian to bring (maximal) energy to the Kidneys.

e. Stimulate with needles the Kidney meridian to bring (maximal) energy to the Liver.
The organs, besides being related with proportional dependences (solid lines on Figure 1), ${ }^{4}$ are also related with reciprocal dependences (dashed lines on Figure 1). The pentagram on Figure 1 reflects both types of dependences.

\begin{tabular}{|c|c|c|c|c|c|}
\hline & Wood & Earth & Fire & Metal & Water \\
\hline $\begin{array}{l}\text { Solid Organs } \\
\text { (Yin) }\end{array}$ & Liver(LR) & $\begin{array}{l}\text { Spleen } \\
(\mathrm{SP})\end{array}$ & $\begin{array}{l}\text { Heart/ } \\
\text { Pericardium } \\
\text { HT/PC }\end{array}$ & $\begin{array}{l}\text { Lungs } \\
\text { (LU) }\end{array}$ & $\begin{array}{l}\text { Kidney } \\
(\mathrm{KI})\end{array}$ \\
\hline $\begin{array}{l}\text { Hollow } \\
\text { Organs (Yang) }\end{array}$ & $\begin{array}{l}\text { Gall- } \\
\text { bladder } \\
(\mathrm{GB})\end{array}$ & $\begin{array}{l}\text { Stomach } \\
\text { (ST) }\end{array}$ & $\begin{array}{l}\text { Small } \\
\text { Intestine } \\
\text { SI/TB }\end{array}$ & $\begin{array}{l}\text { Large } \\
\text { Intestine } \\
\text { (LI) }\end{array}$ & $\begin{array}{l}\text { Bladder } \\
\text { (BL) }\end{array}$ \\
\hline Taste & sour & sweet & bitter & spicy & salty \\
\hline Sensors & eyes & mouth & tong & nose & ears \\
\hline Body parts & $\begin{array}{l}\text { muscles } \\
\text { tendons }\end{array}$ & flesh & $\begin{array}{l}\text { blood } \\
\text { vessels }\end{array}$ & $\begin{array}{l}\text { skin, } \\
\text { body } \\
\text { hair }\end{array}$ & $\begin{array}{l}\text { bones, } \\
\text { hair }\end{array}$ \\
\hline Emotion & anger & $\begin{array}{l}\text { over- } \\
\text { thinking }\end{array}$ & joy & grief & fear \\
\hline Colors & green & yellow & red & white & black \\
\hline Sound & shouting & sing & laugh & wail & groan \\
\hline Season & spring & $\begin{array}{l}\text { late } \\
\text { summer }\end{array}$ & summer & fall & winter \\
\hline Direction & east & center & south & west & north \\
\hline
\end{tabular}




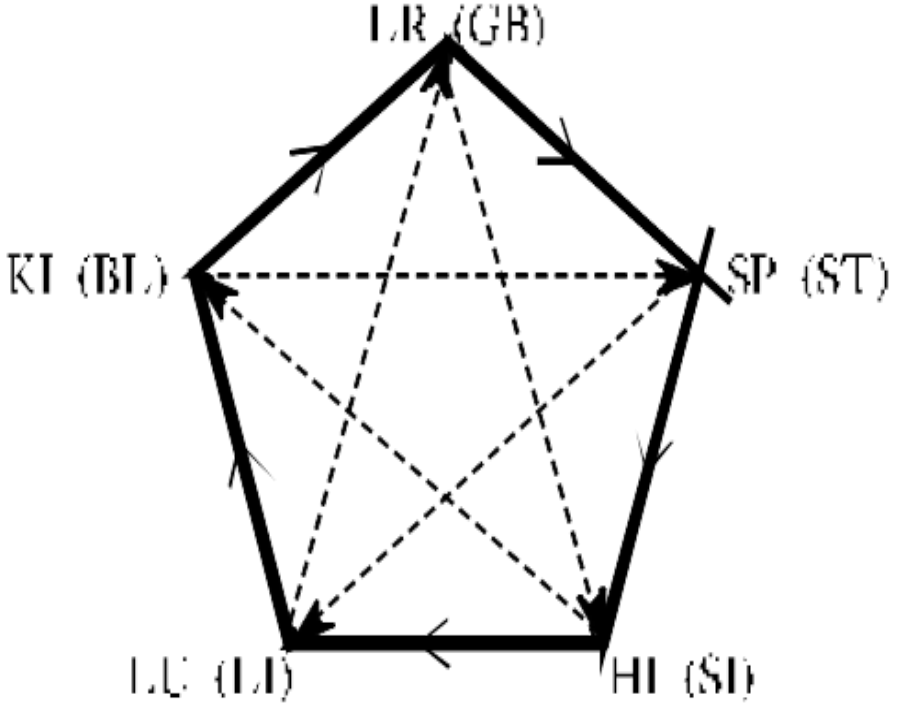

Figure I The organs, besides being related with proportional dependences.

In this pentagram, the solid lines reflect the proportional dependences, while the dashed lines reflect the reciprocal dependences. Both, the proportional and reciprocal dependencies of the organs must be taken into consideration when acupuncture treatments are done (Huang Ti Nei Ching Sue Wen). ${ }^{3}$

\section{Reciprocal dependencies}

The reciprocal dependencies among organs, described in the ancient acupuncture book Huang Ti Nei Ching Sue $\mathrm{Wen}^{3}$ on p. 137, are presented with doted lines on the pentagram of Figure 1. Since every practicing acupuncturist must remember these reciprocal dependencies among the organs to be able to use them in practice, to each organ was ascribed an element (Wood, Fire, Water, Metal, and Earth). By knowing how these elements interact with each other in everyday life, the acupuncturist would know how the organs, ascribed to these elements, interact with each other.

a. Stimulate the Heart (Fire) meridian to suppress the Liver (Wood) function because the Heart element is Fire and Fire would destroy Wood (Liver).

b. Stimulate the Kidney (Water) meridian to suppress the Heart (Fire) function because the Kidney element is Water and Water would extinguish Fire (Heart).

c. Stimulate the Spleen (Earth) meridian to suppress the Kidney (Water) function because the Spleen element is Earth and Earth would overcome Water (Kidneys).

d. Stimulate the Lung (Metal) meridian to suppress the Liver (Wood) function because the Lungs element is Metal and Metal would cut Wood (Liver).

The reciprocal dependences reflect "the effect of counteraction of the five elements and their respective seasons" says the ancient acupuncture book Huang Ti Nei Ching Sue Wen ${ }^{3}$ on p. 137:
a. "Spring counteracts the long Summer.
b. The long Summer counteracts Winter.
c. Winter counteracts Summer.
d. Fall counteracts Spring."

Wood is the element of the Liver, which is maximally active in the Spring and Fire is the element of Heart, which is maximally active in the Summer. Since Fire burns the Wood, this means that by suppressing with needles the Heart (Fire) meridian, the acupuncturist can stimulate the Liver (Wood) (reciprocal dependence).

\section{What should an acupuncturist do, if the heart is overactive?}

If the Heart is overactive, the acupuncturist shouldn't touch the Heart (Fire) meridian. He should stimulate the Kidney (Water) meridian instead because Water extinguishes Fire. It also means that by stimulating the Kidney (Water) meridian in the Winter the acupuncturist can prevent an overactive Heart (Fire) in the Summer.

Water is the element of Kidneys, which are maximally active in the Winter, and Earth is the element of Spleen, which is maximally active in the Summer. Since Earth overcomes Water, this means that the acupuncturist must suppress the Kidney (Water) function to stimulate the Spleen (Earth) meridian.

Metal is the element of Lungs, which are maximally active in the fall, and Wood is the element of Liver, which is maximally active in the spring. Since Metal cuts Wood, the acupuncturist must stimulate the Lung (Metal) meridian in the fall to achieve suppression of the Liver (Wood) function in the spring or vice-versa suppress the Lung (Metal) meridian in the fall to achieve activation of the Liver (Wood) function in the spring.

Thus, the elements: Metal, Wood, Water, Fire, etc. were attached to each pair of coupled organs to help the acupuncturist remember the reciprocal dependencies of the organs. The coupled organs are functionally very closely related and their meridians form closed circle. For example, coupled organs are: Liver and Gall Bladder, Spleen and Stomach, Heart and Small Intestines, Lungs and Large Intestines, and Kidneys and Bladder. The acupuncturist knows from his everyday life experiences that Water extinguishes Fire and Metal cuts Wood. This helps him remember that he needs to stimulate the Water (Kidney) meridian to calm down an overactive Heart (Fire), stimulate the Lung (Metal) meridian to suppress Liver (Wood) function, etc.

\section{Body parts and organs}

Different organs rule different parts of the body:

$i$. Tendons and nails are ruled by the Liver.

ii. Blood vessels are ruled by the heart.

iii. Flesh and muscles are ruled by the Spleen.

iv. Skin and body hair are ruled by the Lungs.

v. Bones and head hair are ruled by the Kidneys (p. 200). ${ }^{3}$

\section{Taste and organs}

Our food should be well balanced if we want to be healthy because balanced taste leads to balanced organs. In the ancient book Huang Ti Nei Ching Sue Wen (p. 200) ${ }^{3}$ it is written:

i. "One must eat spicy hot food to supplement the function of the liver and sour food to drain and expel."

ii. "One must eat salty food to supplement and strengthen the function of the heart and sweet food to drain and dispel." 
iii. "One must eat sweet food to supplement and strengthen the function of the spleen and bitter food to drain."

iv. "One must eat sour food to supplement and strengthen the function of the lungs and spicy hot food to expel."

v. "One must eat bitter food to supplement and strengthen the function of the kidneys and salty food to drain them and to make them expel."

The damage of excess salty, sour, sweet, bitter, and pungent food is listed in the book Huang Ti Nei Ching Sue Wen. ${ }^{3}$

i. "If too much salt is used in the food, the pulse hardens, the tears run easily, and the complexion changes." This is specific for heart disease.

ii. "If too much bitter is used in the food, the skin becomes withered and the body hair falls out." This is specific for kidney disease.

iii. "If too much pungent or spicy hot food is used, the muscles become knotty and the fingernails and toenails wither and decay." This is specific for liver disease.

iv. "If too much sour is used in the food, the flesh hardens and wrinkles and the lips become slack." This is specific for lung disease.

v. "If too much sweet is used in the food, the bones ache and the hair on the head falls out." This is specific for spleen disease.

In the same book ${ }^{3}$ on p. 207 it is written:

i. "The salt goes into the blood. When there is a disease of the blood, one should not eat too much salt."

ii. "The bitter goes into the bones. When there is a disease of the bones, one should not eat too much bitter food."

iii. "The spicy hot flavor goes to the respiratory tract. When there is an illness of the respiratory tract, one should not eat too much spicy hot food."

\section{Senses and organs}

Each of our senses - eyes, ears, nose, mouth, and tongue - is related to a specific organ (Huang Ti Nei Ching Sue Wen). ${ }^{3}$

a. "The Liver rules over the Eyes.

b. The Heart rules over the Tongue.

c. The Spleen rules over the Mouth.

d. The Lungs rule over the Nose.

e. The Kidneys rule over the Ears."

This means

a. Liver disease or weakness would impair eyesight.

b. Heart disease or weakness would impair taste.

c. Spleen disease or weakness would impair the mouth (the salivary glands).

d. Lung disease or weakness would impair the ability to smell.

e. Kidney disease or weakness would impair hearing.

My father died of kidney disease at the age of 48 after suffering of kidneys' attacks for 30 years. He was hard of hearing many years before he died. My mother had asthma for 40 years and she died of lung weakness at age 75 . She couldn't smell many years before she died. The scientific fact that our vision depends on retinene, which is produced by the liver, proves the relation Liver - Eyes.

Besides,

- "Tears are related to the liver.

- Sweating is related to the heart.

- Saliva is related to the spleen.

- Mucous is related to the lungs.

- Urine is related to the kidneys."

Huang Ti Nei Ching Sue Wen ([3], p. 207)

The relation saliva - spleen explains why people with spleen disease or spleen weakness will have a dry mouth. This means that the Spleen rules and regulates the secretion of the salivary glands in the mouth.

\section{Emotions and Organs}

Our emotions influence different organs through the released hormones and neurotransmitters, which cause:

- "joy to emanate from the heart,

- pity to emanate from the lungs,

- grief to emanate from the liver,

- anxiety to emanate from the spleen,

- fears to emanate from the kidneys."

Huang Ti Nei Ching Sue Wen ([3], p. 207)

1. "The emotion of anger arises from fullness of the liver.

2. The emotion of sympathy arises from fullness of the lungs.

3. The emotion of joy arises from fullness of the heart.

4. The emotion of fear releases impulses to the spleen.

5. The feeling of worry releases impulses from the heart."

Huang Ti Nei Ching Sue Wen ([3], p. 181)

1. "Extreme anger is injurious to the liver, but sympathy counteracts anger as spicy hot flavor counteracts the sour flavor.

2. Extreme joy is injurious to the heart, but fear counteracts happiness as salt counteracts the bitter flavor.

3. Extreme sympathy is injurious to the stomach, but anger counteracts sympathy as sour flavor counteracts the sweet flavor.

4. Extreme grief is injurious to the lungs, but joy counteracts grief as bitter flavor counteracts the spicy hot flavor.

5. Extreme fear is injurious to the kidneys, but contemplation counteracts fear as salt is injurious to the blood, but sweet counteracts salt."'Huang Ti Nei Ching Sue Wen. ${ }^{3}$

"Violent anger is hurtful to Yin, violent joy is hurtful to Yang" ([3], p. 117). Therefore, both excess anger and excess joy can destroy the 
balance of Yin and Yang in the body and thus cause a disease.

\section{World's directions and the body}

East and South are Yang because East means light (the Sun appears from the East), and South means warm, and both light and warm activate (Yang) the processes in the body.

West and North are Yin because West means dark (the Sun sets in the West) and North means cold and both dark and cold make the processes in the body less active or passive (Yin).

a. "East means sunrise in the morning, light, warmth, and activation (Yang) of processes in the body by light (Yang), or activation of the processes in the spring when the liver is most active. Therefore, East is the Liver.

b. West is where the Sun sets in the evening, or the day ends to give place to darkness (Yin). This is when the processes in the body slow down (Yin). They also slow down in the Fall when the lungs are most active. Therefore, West is the Lungs.

c. South is warmth (Yang) and warm makes the processes in the body run faster (Yang). This is specific for the summer and in the summer the heart is most active. Therefore, South is the Heart.

d. North is cold (Yin) and cold slows down (Yin) the processes in the body. This is specific for the winter and in the winter the kidneys are most active. Therefore, North is the Kidneys.

e. Spleen is the element of Earth and Earth is in the Center under us. Thus, the Center is the Spleen (Earth). "The ancient sages faced the South and thus they established themselves."

In other words, during the day, when the processes in the body are active (Yang), everyone who is wise should face South or East, which are Yang. Always, when meditating Yogi face East and the altars in all churches face East for a good reason. The Christian churches were built on top of the temples of the old religion called 'old doctrine'. Even the name 'altar' was borrowed from them, which means a place that can 'alter' state of consciousness.

When you sleep, the processes in the body are passive or Yin Therefore, during sleep your head should be toward North (Yin) or West (Yin), which means passive (Yin). Why?

First, contemporary studies show that our body is a magnetic dipole. The head itself has many magnet dipoles oriented with their southern poles out. When our head is oriented toward North, the energy is minimal, which will bring maximal rest. Even the dead were buried either with head to the North (Christian burials near Qumran) or to the West (Arab and Jewish burials).
Second, contemporary studies also show that our body is an electric dipole - the head is positively charged, the legs negatively charged. Our Earth is electrically asymmetric in direction East - West. East is active (Yang), but Yang also means positive electric charges. West is passive (Yin), but Yin also means more negative electric charges. Considering this, for a good rest we should orient our head, which is positively charged, toward West, which is negatively (Yin) charged. Head toward west orientation corresponds to minimal energy of an electric dipole in electric field.

Additional information can be found in the author's book: Maria Kuman, Ancient Wisdom and Modern Science about Health and Happiness. ${ }^{5}$

\section{Conclusion}

This article revealed the reciprocal dependences in the Law of Five Elements and their application in acupuncture practice. The revealed relation organs - taste helps the acupuncturist chose the right diet for his patient; the relation organs - senses serves the purpose to confirm the diagnosis of the acupuncturist; the relation organ-emotions helps the acupuncturist find out what kind of emotions caused the disease.

\section{Acknowledgments}

None.

\section{Conflicts of interest}

Author declares their is no conflicts of interest towards the article.

\section{References}

1. Kuman M. Modern Aspects of Ancient Acupuncture. Health and Happiness Books, 1997. $2^{\text {nd }}$ edn, 2008; $3^{\text {rd }}$ edn 2012

2. Manaka Y, Itaya K, Birch S. Chasing the dragon's tail: the theory and practice of acupuncture in the work of Yoshio Manaka. Brookline, USA: Paradigm Publications Paradigm; 1995.

3. Veith I. Huang Ti Nei Ching Su Wen The Yellow Emperor's Classic of Internal Medicine New Edition Chapters 1-34 Translated from the Chinese with an Introductory Study. Berkley-Los Angeles-London: University of California Press; 1972.

4. Kuman M. Acupuncture meridians and their internal dependence reflected in the ancient laws for practical use. Int J Complement Alt Med. 2018;11(3):173-178.

5. Kuman M. Ancient Wisdom and Modern Science about Health and Happiness. $2^{\text {nd }}$ edn. USA; Health and Happiness Books; 2010. 